\title{
Sulfadiazine-selective determination in aquaculture environment: Selective potentiometric transduction by neutral or charged ionophores
}

\author{
S.A.A. Almeida, A.M. Heitor, M.C.B.S.M. Montenegro, M.G.F. Sales
}

ABSTRACT

\begin{abstract}
Solid-contact sensors for the selective screening of sulfadiazine (SDZ) in aquaculture waters are reported. Sensor surfaces were made from PVC membranes doped with tetraphenylporphyrin-manganese(III) chlo- ride, $a$-cyclodextrin, 13-cyclodextrin, or 1-cyclodextrin ionophores that were dispersed in plasticizer. Some membranes also presented a positive or a negatively charged additive. Phorphyrin-based sen- sors relied on a charged carrier mechanism. They exhibited a near-Nernstian response with slopes of $52 \mathrm{mV}$ decade $^{-1}$ and detection limits of $3.91 \times 10^{-5} \mathrm{~mol} \mathrm{~L}-1$. The addition of cationic lipophilic compounds to the membrane originated Nernstian behaviours, with slopes ranging 59.7-62.0 $\mathrm{mV}$ decade ${ }^{-1}$ and wider linear ranges. Cyclodextrin-based sensors acted as neutral carriers. In general, sensors with positively charged additives showed an improved potentiometric performance when compared to those without additive. Some SDZ selective membranes displayed higher slopes and extended linear concentration ranges with an increasing amount of additive (always $<100 \%$ ionophore). The sensors were independent from the pH of test solutions within $2-7$. The sensors displayed fast response, always $<15 \mathrm{~s}$. In general, a good discriminating ability was found in real sample environment. The sensors were successfully applied to the fast screening of SDZ in real waters samples from aquaculture fish farms. The method offered the advantages of simplicity, accuracy, and automation feasibility. The sensing membrane may contribute to the development of small devices allowing in locus measurements of sulfadiazine or parent-drugs.
\end{abstract}

Keywords

Sulphadiazine, Cyclodextrin-based ionophore, Porphyrin-based ionophore, Sensor, Potentiometry

\section{Introduction}

Aquaculture is the farming of aquatic organisms, practiced for centuries. This practice is today accompanied by the introduction of many chemical substances for therapeutic or prophylactic purposes. Particular attention is given to the use of antibiotics since they enter the environment once leached from faeces and/or uneaten antibiotic feed. Most of the antibiotics given in feed are exported to the surrounding environment and accumulate in the sediment. Thus, theroutineanalytical control of aquaculturewaters should contribute to decrease this environmental contamination.

Sulfonamides are among the most used antibiotics in European countries with contributions between 11 and 24\% [1]. They have been used in human medicine against a wide variety of microbes, being their current use primarily in the treatment of urinary tract infections and in farm animal feedstuff and fish cultures as veterinary drugs [2]. Consequently, sulfonamides may reach the foodchain by means of meat or water contamination by transport through soil or surface runoff and uptake by plants [3,4]. Besides possible adverse effects on microorganisms, the major risk of introducing antibiotics into the environment is the development and spreading of resistant pathogens [4].

Sulfonamides are $\mathrm{N}$-derivatives of 4-aminobenzenesulphonamide, a large group of synthetic antibacterial compounds. They inhibit the conversion of $p$-aminobenzoic acid, interrupting bacterial use of this compound in the synthesis of folic acid and ultimately of purine and DNA. Due to resistance records in formerly susceptible microorganisms, only a few sulpha drugs are used today, among which sulfadiazine (SDZ, Fig. 1).

The analytical control of SDZ is required in several kinds of samples, such as commercial drugs, and biological and food samples. Ideally, this could be achieved by non-destructive and highly selective/sensitive measurements, such as those employing potentiometric sensors. These have found vast applications in many fields of analysis [5-7]. They offer high precision and rapidity, low cost of analysis, enhanced selectivity and sensitivity over a wide range of concentrations $[8,9]$. In addition, they are easy to construct and manipulate and no sample pretreatment is needed before the 


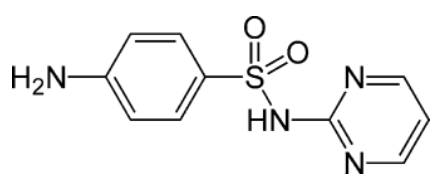

Fig. 1. Chemical structure of SDZ.

analysis itself. Short response times, in the order of seconds, make themappropriatedevicesfor process control and screening analysis $[8,9]$.

Ion-selective membrane sensors, as their name implies, are based on membranes that enable the selective recognition of a specific ion by transferring it (selectively) across the interface between the sample and membrane phase and generating a potential difference [10]. This electrochemical signal is a measure of the activity of that ion. Many mechanisms have been suggested for the selective recognition of different ions [11], most of which mention the selective complexation between the target ion (guest) and a specific carrier (host). This carrier is incorporated in the membrane of the sensor, in order to create the desired selectivity. In general, the overall selectivity of the host-guest interaction depends on several factors such as: (i) the size of the cavity of the host that should be large enough to accommodate the guest species (as the complexation happens, the hydration shell of the target species is removed and substituted by the donor atoms of the host or ligand); (ii) the number of donor atoms in the ligand should be sufficient, to match the coordination number of the targetspecies ; (iii) the flexibility of holding of donor atoms by the host backbone must be limited, so that their positions are suitable to match the shape of the coordination sphere of the target species [12].

An obvious binding strategy for anionic species such as SDZ is to use a positively charged host molecule. However, electrostatic interactions are non-directional and all anions may bind to cations and form either a solvent-separated or contact-ion pair. Anions also bind neutral receptors when there is a difference in electrostatic charge [13]. Thus, neutral or charged carriers, such as cyclodextrin(CD) or porphyrin (PPHR) derivatives may beemployed for the potentiometric transduction of SDZ.

CDs are the most widely used receptors in host-guest inclusion chemistry $[13,14]$. They are a family of cyclic oligosaccharides with a variable number of d-glucopyranoside units linked by 1,4glycosidic bonds. CDs possess a cage-like supramolecular structure that is generally represented as a cylindrical funnel with an upper (wide) and lower (narrow) rim. The upper rim consists of the secondary hydroxyl groups and the lower of primary hydroxyl groups [13]. It allows carrying out chemical reactions involving "host-guest" electrostatic interactions of intramolecular nature. No covalent bonds are formed or broken in this context. The main driving force of complex formation is the release of enthalpy-rich water molecules from the cavity; water molecules are displaced by more hydrophobic guest molecules present in the solution to attain an apolar-apolar association, resulting in a more stable lower energy state [14].

The PPHR molecule contains four pyrrole rings linked via methine ( $€ \mathrm{H}-$ ) bridges and exhibits aromatic character. The PPHR nucleus is a tetradentate ligand in which there is space available for a coordinated metal. When coordination occurs, two protons are removed from the pyrrole nitrogen atoms, leaving two negative charges [15]. PPHR complexes with transition metal ions are very stable and are often used to construct structures in supramolecular chemistry, taking advantage of the Lewis acidity of the coordinated metal [16]. Several metalloporphyrins have been employed as electroactive components in the membrane of potentiometric sensors, and their response to anions has been interpreted by a dissociation ion-exchange mechanism or metal-ligand interaction mechanism [16-20].

In the presented work, new potentiometric sensors are proposed for SDZ by doping PVC membranes with neutral (CD) or charged ionophores (PPHR) that selectively and reversibly form complexes with the analyte. In addition, it is well known that the nature/amount of ionophore and additives in the selective membrane affect the analytical performance of a potentiometric sensor. A literature survey showed that the usual range of composition in the preparation of PVC matrix membrane sensor was $1-7 \%$ ionophore, 28-33\% PVC (internal matrix), 60-69\% plasticizer (solvent) and $0.03-2 \%$ lipophylic additive [21]. Hence, in this work, SDZ sensors were prepared in a similar way, having CD or PPHR based different electroactive materials and different additives in different amounts. Only $o$-nitrophenyl octyl ether $(o$-NPOE) was used as plasticizer, according to a previous study on porphyrin-based sensors [22]. The response behavior of the corresponding sensors is reported herein.

\section{Experimental}

\subsection{Reagents and solutions}

All reagents were of analytical grade without further purification. SDZ, tetraoctylammonium bromide (TOABr), dimethyldioctadecylammonium bromide (DDABr), tetrakis (4-chlorophenyl) borate (KTpClPB), tetrahydrofuran (THF), alpha, beta or gammaCDs (CD), meso-tetraphenylporphyrin manganese (III) chloride complex $\left(\mathrm{Mn}^{\mathrm{III}} \mathrm{TPPCl}\right)$ and high relative molecular weight $\mathrm{PVC}$ were purchased from Sigma-Aldrich. De-ionized water (conductivity $<0.1 \mu \mathrm{S} \mathrm{cm}^{-1}$ ) was employed in all experiments.

Stock solutions of SDZ $0.01 \mathrm{~mol} \mathrm{~L}^{-1}$ were prepared in water. Less concentrated SDZ standards were prepared by suitable dilution in ultra-pure water. Buffer solutions were $0.01 \mathrm{M} 4$-(2-hydroxyethyl)1-piperazineethanesulfonic acid) (HEPES, pH 5.4).

The effect of $\mathrm{pH}$ was studied by imputing $\mathrm{pH}$ variations on $200 \mathrm{~mL}$ of a SDZ solution $1.0 \times 10^{-3} \mathrm{~mol} \mathrm{~L}^{-1}$. The $\mathrm{pH}$ of this solution was altered by little additions of either concentrated sulphuric acid or saturated sodium hydroxide solution, freshly prepared.

Interference of other chemicals was evaluated for $1.2 \times 10^{-4}$, $5.0 \ngtr 0^{-4}$, and $1.01 \mathrm{O}^{-3} \mathrm{~mol} \mathrm{~L}^{-1}$ solutions of sodium carbonate, sodium chloride, sodium fluoride, sodium nitrate, bicarbonate and sodium nitrite. All these solutions were prepared in buffer.

\subsection{Apparatus}

Measurements were carried out with the electrochemical cell $\mathrm{AgCl}(\mathrm{s}) / \mathrm{Ag}$ double junction reference electrode/test solution/SDZ selective membrane, graphite-epoxy. An Orion, 90-00-29, doublejunction electrode was used as reference. Potential differences between indicator and reference electrodes were measured by means of a Crison ${ }^{\circledR} \mathrm{mpH} 2002$ decimilivoltammeter. The analytical output signal was transferred to a commutation point with six ways out, enabling the reading of six sensors dipped in the same solution. Each way presented an electrical antenna connector that provided suitable adaptation to each sensor.

The pHwas measured by a Crison CWL/S7 combined glass electrode connected to a Crison decimilivoltammeter, $\mathrm{pH}$ meter, GLP 22. Spectrophotometric assays were carried out on a Shimadzu Pharmaspec UV-1700.

\subsection{Preparation of the $S D Z$ sensor}

The sensors used an epoxy-graphite matrix as solid contact [9]. This matrix was prepared by mixing Araldit/Hardener with graphite powder in a 1:1 $(\mathrm{w} / \mathrm{w})$ ratio and placed before dry on 
Table 1

Membrane composition of SDZ sensors.

\begin{tabular}{|c|c|c|c|c|c|c|c|c|c|}
\hline \multirow[t]{2}{*}{ ISE } & \multicolumn{4}{|c|}{ Membrane composition } & \multirow[t]{2}{*}{ Slope $\left(\mathrm{mV}\right.$ decade ${ }^{-1}$ ) } & \multirow[t]{2}{*}{$R^{2}(n=4)$} & \multirow[t]{2}{*}{$\operatorname{LOD}\left(\mathrm{mol} \mathrm{L}^{-1}\right)$} & \multirow[t]{2}{*}{$\operatorname{LLLR}\left(\mathrm{mol} \mathrm{L}^{-1}\right)$} & \multirow{2}{*}{$\begin{array}{l}\text { Response } \\
\text { time (s) }\end{array}$} \\
\hline & Active ingredient & Plasticizer & Additive & Weight (mg) & & & & & \\
\hline 1 & $\mathrm{Mn}^{\mathrm{III}} \mathrm{TPPCl}$ & $o$-NPOE & - & $5.5: 370$ & $51.70 \pm 2.10$ & 0.9946 & $3.88 \times 10^{-5}$ & $1.28 \times 10^{-4}$ & $<15$ \\
\hline 2 & $\mathrm{Mn}^{\mathrm{III}} \mathrm{TPPCl}$ & $o$-NPOE & TOABr & 5.5:370:1.1 & $58.66 \pm 0.95$ & 0.9933 & $3.43 \times 10^{-5}$ & $1.13 \times 10^{-4}$ & $<15$ \\
\hline 3 & $\mathrm{Mn}^{\mathrm{III}} \mathrm{TPPCl}$ & $o$-NPOE & $\mathrm{TOABr}$ & $5.5: 370: 2.1$ & $60.23 \pm 1.20$ & 0.9956 & $2.55 \times 10^{-5}$ & $8.41 \times 10^{-5}$ & $<15$ \\
\hline 4 & $\mathrm{Mn}^{\mathrm{III}} \mathrm{TPPCl}$ & $o$-NPOE & $\mathrm{TOABr}$ & $5.5: 370: 4.3$ & $61.42 \pm 0.81$ & 0.9956 & $2.99 \times 10^{-5}$ & $9.87 \times 10^{-5}$ & $<15$ \\
\hline 5 & $\mathrm{Mn}^{\mathrm{III}} \mathrm{TPPCl}$ & $o$-NPOE & $\mathrm{DDABr}$ & $5.5: 370: 1.2$ & $59.11 \pm 2.26$ & 0.9938 & $2.10 \times 10^{-5}$ & $6.94 \times 10^{-5}$ & $<15$ \\
\hline 6 & $\mathrm{Mn}^{\mathrm{III}} \mathrm{TPPCl}$ & $o$-NPOE & $\mathrm{DDABr}$ & $5.5: 370: 2.4$ & $62.02 \pm 2.66$ & 0.9940 & $2.10 \times 10^{-5}$ & $6.94 \times 10^{-5}$ & $<15$ \\
\hline 7 & $\mathrm{Mn}^{\mathrm{III}} \mathrm{TPPCl}$ & $o$-NPOE & $\mathrm{DDABr}$ & $5.5: 370: 4.9$ & $61.89 \pm 2.85$ & 0.9953 & $2.10 \times 10^{-5}$ & $6.94 \times 10^{-5}$ & $<15$ \\
\hline 8 & $\mathrm{Mn}^{\mathrm{III}} \mathrm{TPPCl}$ & $o$-NPOE & KTpCIPB & 5.5:370:1.0 & $26.57 \pm 0.68$ & 0.9948 & $2.10 \times 10^{-5}$ & $6.94 \times 10^{-5}$ & $<15$ \\
\hline 9 & $\mathrm{Mn}^{\mathrm{III}} \mathrm{TPPCl}$ & $o$-NPOE & KTpCIPB & 5.5:370:1.9 & $36.30 \pm 2.92$ & 0.9932 & $2.55 \times 10^{-5}$ & $8.41 \times 10^{-5}$ & $<15$ \\
\hline 10 & $\mathrm{Mn}^{\mathrm{III}} \mathrm{TPPCl}$ & $o$-NPOE & KТрСІРB & 5.5:370:3.9 & $43.40 \pm 0.92$ & 0.9966 & $2.55 \times 10^{-5}$ & $8.41 \times 10^{-5}$ & $<15$ \\
\hline 11 & $a-\mathrm{CD}$ & $o$-NPOE & - & $5.5: 370$ & - & & & & \\
\hline 12 & $a-\mathrm{CD}$ & $o$-NPOE & TOABr & 5.5:370:0.8 & $47.56 \pm 0.66$ & 0.9934 & $3.91 \times 10^{-5}$ & $1.29 \times 10^{-4}$ & $<15$ \\
\hline 13 & $a-\mathrm{CD}$ & $o$-NPOE & TOABr & 5.5:370:1.5 & $54.85 \pm 0.51$ & 0.9979 & $2.56 \times 10^{-5}$ & $8.46 \times 10^{-5}$ & $<15$ \\
\hline 14 & $a-\mathrm{CD}$ & $o$-NPOE & $\mathrm{TOABr}$ & 5.5:370:3.1 & $53.27 \pm 1.93$ & 0.9946 & $1.88 \times 10^{-5}$ & $6.21 \times 10^{-5}$ & $<15$ \\
\hline 15 & $a-\mathrm{CD}$ & $o$-NPOE & $\mathrm{DDABr}$ & 5.5:370:0.9 & $52.71 \pm 0.82$ & 0.9948 & $4.95 \times 10^{-5}$ & $1.63 \times 10^{-4}$ & $<15$ \\
\hline 16 & $a-\mathrm{CD}$ & $o$-NPOE & $\mathrm{DDABr}$ & 5.5:370:1.8 & $59.30 \pm 3.36$ & 0.9946 & $1.20 \times 10^{-5}$ & $3.97 \times 10^{-5}$ & $<15$ \\
\hline 17 & $a-\mathrm{CD}$ & $o$-NPOE & $\mathrm{DDABr}$ & 5.5:370:3.5 & $64.66 \pm 1.03$ & 0.9940 & $1.80 \times 10^{-5}$ & $5.94 \times 10^{-5}$ & $<15$ \\
\hline 18 & $13-\mathrm{CD}$ & $o$-NPOE & - & $5.5: 370$ & - & & & & \\
\hline 19 & $13-\mathrm{CD}$ & $o$-NPOE & TOABr & 5.5:370:0.6 & $49.79 \pm 1.61$ & 0.9935 & $3.43 \times 10^{-5}$ & $1.13 \times 10^{-4}$ & $<15$ \\
\hline 20 & $13-\mathrm{CD}$ & $o$-NPOE & $\mathrm{TOABr}$ & $5.5: 370: 1.3$ & $57.17 \pm 1.49$ & 0.9960 & $1.87 \times 10^{-5}$ & $6.19 \times 10^{-5}$ & $<15$ \\
\hline 21 & $13-\mathrm{CD}$ & $o$-NPOE & $\mathrm{TOABr}$ & $5.5: 370: 2.6$ & $65.31 \pm 1.07$ & 0.9957 & $1.21 \times 10^{-5}$ & $3.98 \times 10^{-5}$ & $<15$ \\
\hline 22 & $13-\mathrm{CD}$ & $o$-NPOE & $\mathrm{DDABr}$ & $5.5: 370: 0.7$ & $59.13 \pm 0.27$ & 0.9937 & $3.91 \times 10^{-5}$ & $1.29 \times 10^{-4}$ & $<15$ \\
\hline 23 & $13-\mathrm{CD}$ & $o$-NPOE & $\mathrm{DDABr}$ & 5.5:370:1.5 & $60.47 \pm 1.56$ & 0.9942 & $4.71 \times 10^{-5}$ & $1.56 \times 10^{-4}$ & $<15$ \\
\hline 24 & $13-\mathrm{CD}$ & $o$-NPOE & $\mathrm{DDABr}$ & 5.5:370:3.1 & $59.08 \pm 0.90$ & 0.9949 & $2.71 \times 10^{-5}$ & $8.94 \times 10^{-5}$ & $<15$ \\
\hline 25 & $1-\mathrm{CD}$ & $o$-NPOE & - & $5.5: 370$ & - & & & & \\
\hline 26 & $1-\mathrm{CD}$ & $o$-NPOE & $\mathrm{TOABr}$ & 5.5:370:0.6 & $52.10 \pm 1.91$ & 0.9963 & $3.31 \times 10^{-5}$ & $1.09 \times 10^{-4}$ & $<15$ \\
\hline 27 & $1-C D$ & $o$-NPOE & TOABr & 5.5:370:1.2 & $64.96 \pm 1.35$ & 0.9960 & $1.21 \times 10^{-5}$ & $3.99 \times 10^{-5}$ & $<15$ \\
\hline 28 & $1-C D$ & $o$-NPOE & TOABr & $5.5: 370: 2.3$ & $65.16 \pm 1.28$ & 0.9952 & $1.21 \times 10^{-5}$ & $3.99 \times 10^{-5}$ & $<15$ \\
\hline 29 & $1-\mathrm{CD}$ & $o$-NPOE & $\mathrm{DDABr}$ & 5.5:370:0.7 & $51.92 \pm 1.14$ & 0.9926 & $4.68 \times 10^{-5}$ & $1.55 \times 10^{-4}$ & $<15$ \\
\hline 30 & $1-\mathrm{CD}$ & $o$-NPOE & $\mathrm{DDABr}$ & 5.5:370:1.3 & $56.07 \pm 0.91$ & 0.9973 & $4.95 \times 10^{-5}$ & $1.63 \times 10^{-4}$ & $<15$ \\
\hline 31 & $1-\mathrm{CD}$ & $o$-NPOE & $\mathrm{DDABr}$ & $5.5: 370: 2.7$ & $63.70 \pm 3.07$ & 0.9975 & $2.54 \times 10^{-5}$ & $8.40 \times 10^{-5}$ & $<15$ \\
\hline
\end{tabular}

top of a cylindrical body. Each PVC membrane was prepared by mixing $5.5 \mathrm{mg}$ of active ingredient with $370 \mathrm{mg}$ of $o$-NPOE acting as plasticizer and variable amount/kind of additive (Table 1). The resulting solution was homogenized in a $180 \mathrm{mg}$ of PVC previously dissolved in about $5 \mathrm{~mL}$ THF and casted over the previously indicated a graphite-based conductive supports. Membranes were let dry and conditioned in a $1.0 \times 10^{-3} \mathrm{~mol} \mathrm{~L}^{-1} \mathrm{SDZ}$ aqueous solution before use. The sensors were also kept in this solution when not in use.

\subsection{Potentiometric procedures}

All potentiometric measurements were carried out at room temperature and in solutions of fixed $\mathrm{pH}$ and ionic strength. Calibration curves followed the Litre beaker method [21]. All sensors were placed in a convenient support over a magnetic stirrer and immersed in $50.00 \mathrm{~mL}$ of HEPESCalibration procedures were made by transferring $0.0200-10.0 \mathrm{~mL}$ aliquots of $1.0 \times 10^{-3} \mathrm{~mol} \mathrm{~L}^{-1} \mathrm{SDZ}$ aqueous solution into this electrolyte. The potential readings of the stirred SDZ solutions were measured at room temperature and recorded after stabilization to $\pm 0.2 \mathrm{mV}$. The calibration graph plotted logarithm concentration $\left(\mathrm{mol} \mathrm{L}^{-1}\right)$ against electromotive force $(\mathrm{mV})$.

\subsection{Binding studies}

The binding between $\mathrm{Mn}^{\mathrm{III}} \mathrm{TPPCl}$ or 1-CD and SDZ was monitored at 475 or $300 \mathrm{~nm}$, respectively. These wavelengths were selected by plotting the spectra of a solution with ionophore and analyte with $1.0 \times 10^{-6} \mathrm{~mol} \mathrm{~L}^{-1}$. The spectra of single solutions with $1.0 \star 0^{-6} \mathrm{~mol} \mathrm{~L}^{-1}$ of ionophore or SDZ prepared in HEPES/THF (50:50) was also recorded, serving as blank.
The molar ratio between the analyte and the ligand was calculated by adding $300 \mu \mathrm{L}$ aliquots of a more concentrated SDZ solution to a suitable volume of $1.0 \times 10^{-6} \mathrm{~mol} \mathrm{~L}{ }^{-1}$ ionophore solution. Spectra were recorded for each concentration level of SDZ.

Binding constants were calculated by the Sandwich method. The conductive support of the sensor was first coated with membranes without ionophore and after with membranes carrying the ionophore. The sensors were let stand for $12 \mathrm{~h}$ in 1 . $810^{-2} \mathrm{~mol} \mathrm{~L}^{-1}$ SDZ.

\subsection{Sample preparation}

Samples were collected from several aquaculture units, placed in sweet waters by the north region of Portugal. The waters were collected from the tank itself and from the surroundings, in order to estimate antibiotic dissemination. By the time of collection, there was no previous antibiotic application and these were blank samples. Typically, a dose of $30 \mathrm{mg}$ of active ingredient is administered per $\mathrm{kg}$ bodyweight of fish daily for a period of 7-10 days. Therefore, the waters were spiked taking into consideration the concentrations expected in each tank after application of a commercial formulation with $333.3 \mathrm{~g}$ sulfadiazine per $\mathrm{kg}$. The concentration on samples lied within 25 and $250 \mu \mathrm{g} \mathrm{mL}^{-1}$. The direct potential method was applied to determine SDZ in spiked waters. The analysis was conducted after calibration.

\section{Results and discussion}

Several parameters, such as binding features, calibration slopes, reproducibility, dynamic linear range, limit of detection, response time, effect of $\mathrm{pH}$ and selectivity, were investigated to evaluate the effect of Mn(III) PPHR and CD ionophores on the analytical 
performance of SDZ sensors and the need for a charged additive (membrane composition was indicated in Table 1).

\subsection{Porphyrin as charged ionophore}

Metalloporphyrins are electrically charged carriers in the membrane when uncomplexed and neutral when bounded to anions by axial ligation of the metal center [23]. This ionophore is expected to respond selectively to anionic species such as SDZ if there is a selective coordination of the anion by axial bound to the positively charged metal center.

Thus, the selective interaction between SDZ and the metal center of the PPHR $\left(\mathrm{Mn}^{\mathrm{III}}\right)$ was confirmed by spectrophotometric assays. PPHRs are Naturally Occurring Planar Microcycles with highly sensitive chromogenic properties and their metal chelates generally exhibit characteristic absorption bands in the visible region. The region from 400 to $500 \mathrm{~nm}$, which is called the Soret band, shows the most intensive absorption [16]. $\mathrm{Mn}^{\mathrm{III}} \mathrm{TPPCl}$ provides a Lewis acid binding site for electron donors such as SDZ and the extended $p$-system points out the binding events by means of optical spectrophotometry. Free $\mathrm{Mn}^{\mathrm{III}} \mathrm{TPPCl}$ displayed a sharp absorption band with $475 \mathrm{~nm}$ maximum in HEPES/THF (50:50) medium. Theincreasing addition ofSDZdecreased thisabsorbance, with maximum absorbance at $473 \mathrm{~nm}$, until all PPHR was complexed with the analyte. This was observed when a 1:1 molar ratio of each compound was present (Fig. 2), suggesting that one mole of $\mathrm{Mn}^{\mathrm{III}} \mathrm{TPPCl}$ bound to one mol ofSDZ. The average binding constant between SDZ and Mn ${ }^{\mathrm{III}} \mathrm{TPPCl}$ was 6.40. This value was calculated potentiometrically by means of the Sandwich method.

$\mathrm{Mn}^{\mathrm{III}} \mathrm{TPPCl}$ membrane sensors without additive (Fig. 3, left) exhibited a linear emf response against logarithmic SDZ concentration. They showed near-Nernstian behavior, with averageslopes of $52 \mathrm{mV}$ decade ${ }^{-1}$ from $1.3 \times 10^{-4}$ to $1.0 \notin 0^{-2} \mathrm{~mol} \mathrm{~L}^{-1}$. Although some concerns have been reported in literature about the spontaneous hydroxy-bridged dimer formation of metalloporphyrins in ion-selective membranes originating super-Nernstian response slopes [24-26], this was not observed in the present studies.

\subsection{Cyclodextrin as neutral ionophore}

CDs are widely known by their ability to form an inclusion complex with hydrophobic guest molecules, because their cavity is hydrophilic outside and hydrophobic inside [13]. Although hydrophilic hydroxyl groups occupy both rims of the cone and the inside of the cavity, they are hydrophobic in character for being covered by $\mathrm{C}_{3}-\mathrm{H}, \mathrm{C}_{5}-\mathrm{H}$, and $\mathrm{C}_{6}-\mathrm{H}$ and by the ether link oxygen between each glucopyranosyl units [27].

The more or less extent of each inclusion complex is a function of space or thermodynamic aspects. The former one points out that the size of the CD cavity should fit to the size of the guest molecule. The CDs used in this work were $a-\mathrm{CD}, 13-\mathrm{CD}$ and $1-\mathrm{CD}$. They have six, seven and eight $a-(1,4)$ glycosyl units, respectively, and different cavity sizes. The height of the cavity is equal for all three types, but their diameters vary within $4.7-5.3,6.0-6.5$, and 7.5-8.3 $\AA$, corresponding to estimated volumes of 174,262 , and $427 \AA$ [14]. Based on these dimensions, $a$-CD can typically accommodate the smaller molecules and 1-CD the larger molecules. To know in anticipate which CDcarries the most suitablecavity size to accommodateSDZ is quite difficult because SDZ presents many different conformations and different protonation states varying with the $\mathrm{pH}$. Besides, recent studies have revised the known structure of SDZ, showing that SDZ contains two S-O single bonds instead the typical S-O double bond, bears negative charges over the pyrimidine nitrogen atom and is a very flexible structure [28].

SDZ was studied first as an inclusion guest on thelarger CD host cavity. Binding experiments were carried out by analysing the max- imum absorbance of SDZ, 13-CD and SDZ plus 13-CDUV spectra. The addition of SDZ to 13-CD increased the $300 \mathrm{~nm}$ absorbance. This increase was perceptible after comparing the individual spectra of the two components with that of their mixture. The experimental results suggested that two molecules of SDZ bound to one molecule of CD. Although CDs usually form 1:1 host-guest complexes, 1:2 complexes are also possible [13]. In aqueous solution,

the hydrophobic cavity is filled with water and the weak nature of these apolar-polar interactions replace it by another less polar guest molecule. The average binding constants between SDZ and $a-C d, 13-C d$, and 1-CDwere5.27,5.46, and 5.22, respectively. Aspreviously indicated, these were calculated by the Sandwich method.

Considering CD membranes without additive (Table1), none of the CDs in this study were able to provide a suitable emf variation with SDZ concentration (Fig. 3, left). Since the uncharged carriers are neutral when uncomplexed in the membraneand the

complexes have the same charge as the analyte ion, the respective membranes require the additional incorporation of lipophilic ions of opposite charge to ensure permselectivity [29]. Thus, CD SDZ membrane sensors found essential the inclusion of an ionic additive.

\subsection{Effect of additive}

The role of lipophilic anionic and cationic additives on the potentiometric anion selectivity of the membranes prepared with the PPHR or CD ionophores as anion selective ionophores was examined. Theadditiveswereemployed to produceionic sites among the sensing membranes. Generally, this procedure improves the general analytical response of the potentiometric sensor by ensuring that membranes are perm-selective, reducing the ionic interference and lowering the electrical resistance of the membranes [30]. It may also catalyze the exchange kinetics at the sample-membrane interface and enhance the sensitivity of the membrane [22].

In general, with positively charged receptors, lipophilic anionic sites should be added to the membrane in order to optimize the sensor selectivity, whereas in the case of neutral receptors cationic sites should be added [31,32]. In addition, depending on the organic ligand and the metal center, PPHR receptors applied in potentiometric sensors may contain both charged and neutral receptors. The type of ligand and metal center influence the sensor selectivity due to differences in the electron-accepting character of the complex.

Thus, the additives employed for PPHR-based sensors were either positively (TOABr, DDABr) or negatively charged (KTpClPB) while CD-based sensors had always positively charged additives. All these were sufficiently lipophilic to remain solely in the organic membrane phase when in contact with aqueous solution. The effect of carrier:SDZ molar ratios on the sensor response was studied by doping membranes with 25,50 to $100 \%$ additive relative to the ionophore; the corresponding mass ratios are indicated in Table 1, and vary according to the molar mass of each additive.

As a general rule, the positively charged additives enhanced the sensitivity of the PPHR-based sensors from 52 to $60 \mathrm{mV}$ decade ${ }^{-1}$ (Fig. 3B). A slight increase in slope was also observed for an increasing amount of additive. Both limit of detection (LOD) and lower limit of linear range (LLLR) remained unaffected by the additive amount. In turn, it is believed that the anionic additive acted as an excluder of anionic-species (including SDZ), leading to a decreased sensitivity.

The positive additive played a fundamental role in the CD sensors. TOABr increased more significantly the slopes of the CDs with larger cavities while DDABr increased with more relevance the slopes of the smaller carriers. Comparing CD-based sensors with additive, only those with 13-CD displayed Nernstian behavior, independently of the amount of additive. The other sensors showed increasing sensitivities for an increased amount of additive. 

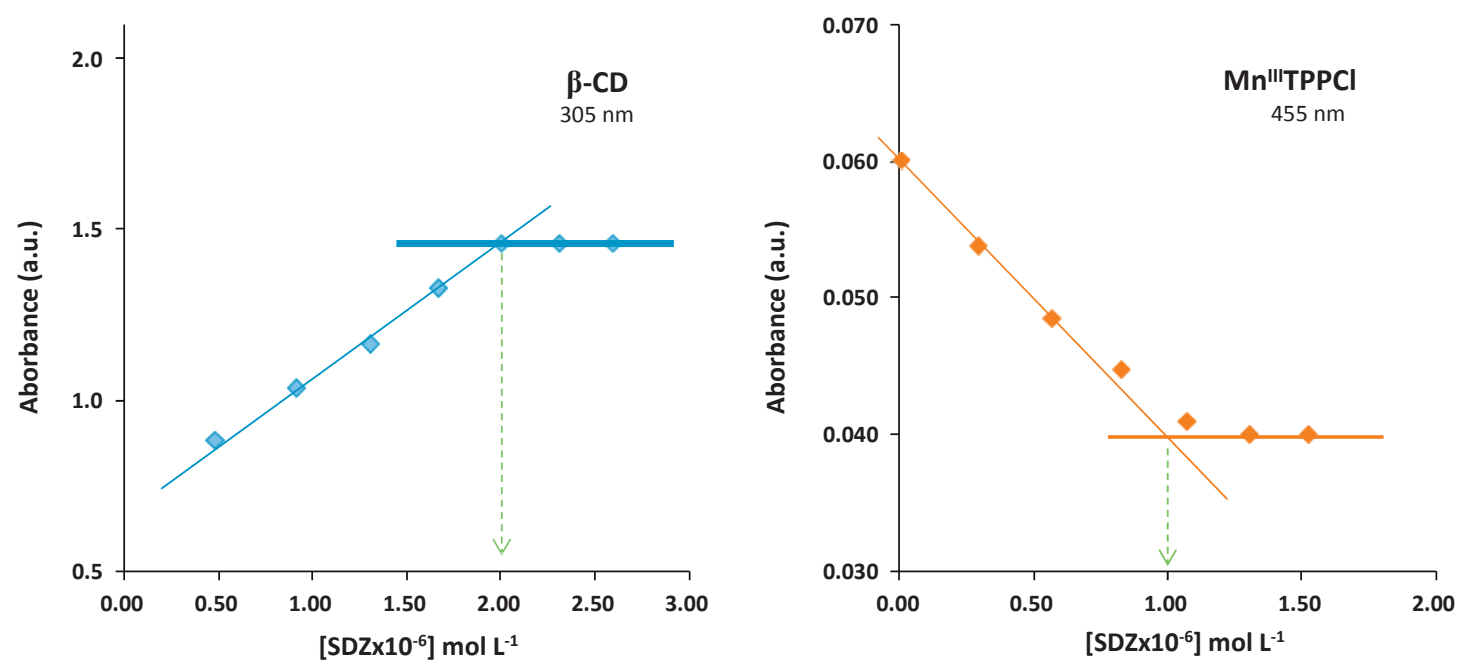

Fig. 2. Molar ratio between SDZ and CD (left) or PPHR (right), for $1.0 \times 10^{-6} \mathrm{~mol} \mathrm{~L}^{-1}$ of ionophore.

Generally, potentiometric sensors with higher amount of additive presented extended working ranges, with lower LLLR and LOD. These results suggest that the cavity size of $13-\mathrm{CD}$ was the most suitable one for interacting with the SDZ hydrophobic portion.

\subsection{Effect of pH}

The effect of $\mathrm{pH}$ on the sensor potential was studied for a SDZ solution of $1 \times 10^{-3} \mathrm{~mol} \mathrm{~L}^{-1}$. The $\mathrm{pH}$ was adjusted by small additions of concentrated sulfuric acid or sodium hydroxide solution and recorded by a combined glass- $\mathrm{pH}$ electrode. When $\mathrm{pH}$ values were plotted against emf $(\mathrm{mV})$, it was observed that the potential was not steady but almost independent from $\mathrm{pH}$ in the range of $2-11.0$, with potential variations within $\underline{\mathbb{1}} 5 \mathrm{mV}$. Consequently, this interval was considered a plausible $\mathrm{pH}$ working range. $a-\mathrm{CD}$ sensors with $\mathrm{DDABr}$ displayed however a potential drop after $\mathrm{pH} 7$, suggesting an $\mathrm{HO}^{-}$interference effect. Sensors with $\mathrm{Mn}^{\mathrm{III}} \mathrm{TPPCl} / \mathrm{KTpClPB}$ behaved like a $\mathrm{pH}$ electrode (Fig. 4), probably in response to its negatively charged additive, present in the same amount as PPHR.

\subsection{Response time, lifetime and validation}

The time required to achieve a steady potential response $( \pm 1 \mathrm{mV})$ for a 10 -fold concentration increase from $5 \times 10^{-5}$ and $1 \notin 0^{-4} \mathrm{~mol} \mathrm{~L}{ }^{-1} \mathrm{SDZ}$ was $<15 \mathrm{~s}$ (Table 1 ). These results indicated that the complexation process between SDZ and the different ionophores was kinetically fast, pointing out that the overall free energy barrier for the free to complexed states was small enough for complexation to occur rapidly. Replicate calibrations for each sensor indicated low potential drift, long-term stability and negligible change in the response of the sensors.

Having sensors stored and conditioned in $1 \times 10^{-3} \mathrm{~mol} \mathrm{~L}^{-1} \mathrm{SDZ}$ solution, the detection limits, response times, linear ranges and calibration slopes were reproducible within $\underline{3} \%$ of their original values, and over a period of at least 2 months. This was the maximum period observed, meaning that the sensors could last longer.

During this period, leaching of electroactive materials from the membranes was not perceptible, and ionophore and additive remained preferentially in the hydrophobic phase. PPHR deriva-
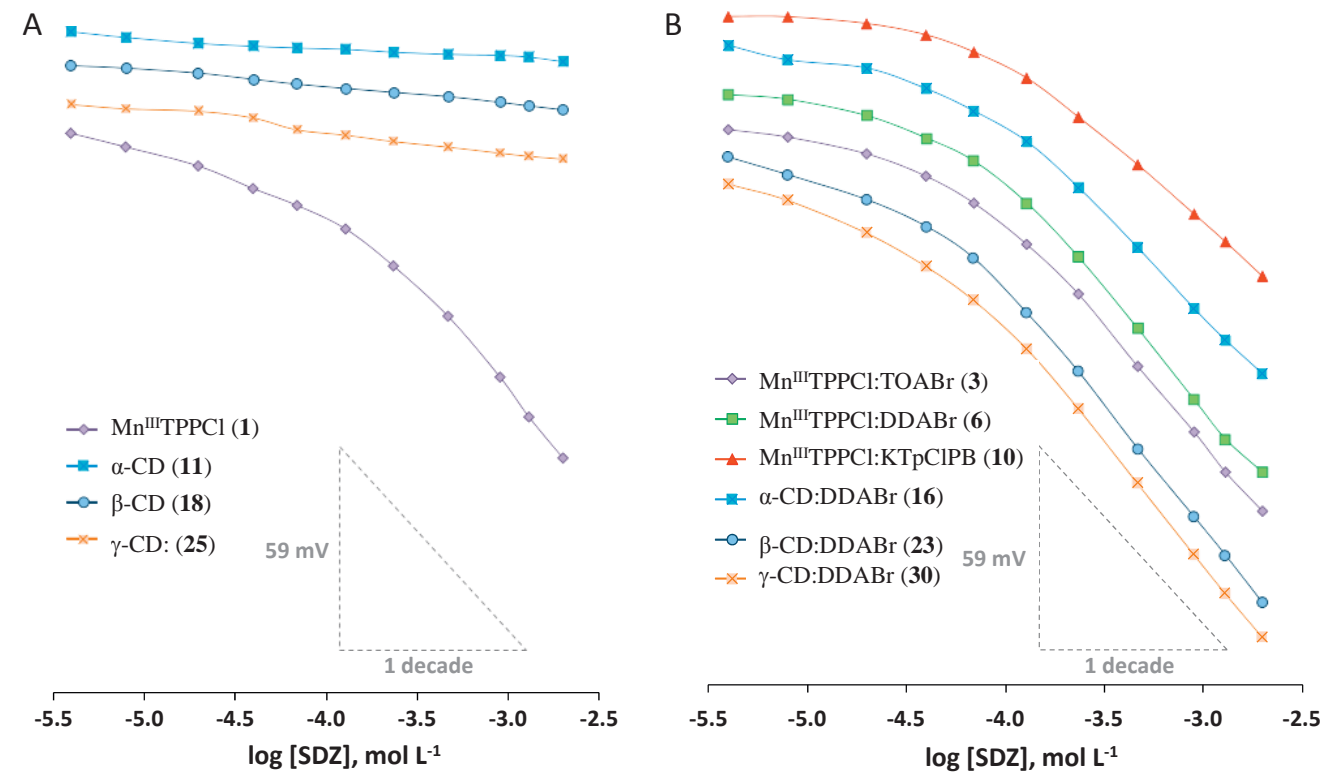

Fig. 3. Typical calibration curves of SDZ sensors without additive (A) or with different additives (B) in HEPES buffer 



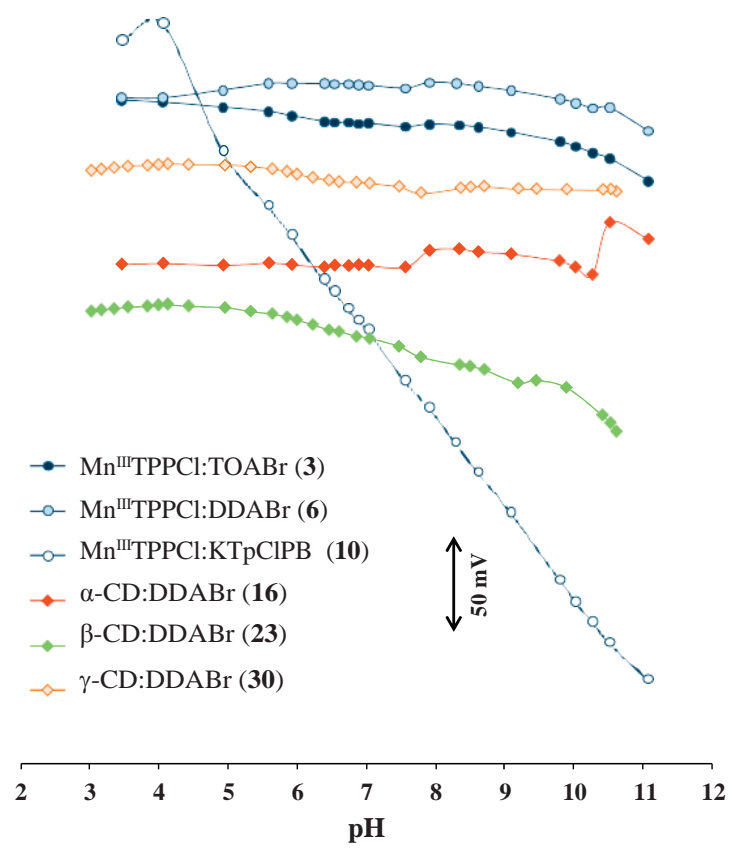

Fig. 4. Influence of $\mathrm{pH}$ on the potentiometric response of SDZ sensor $\left([\mathrm{SDZ}]=1 \times 10^{-3} \mathrm{~mol} \mathrm{~L}^{-1}\right)$.

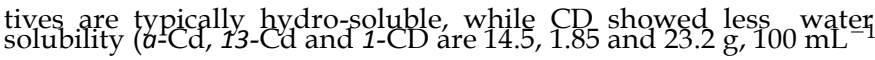

at $20{ }^{\circ} \mathrm{C}$ ). Their aromatic rings or uncharged groups are however responsible for allowing them to stand inside a hydrophobic membrane. The water solubility of the ionic additives is much lower than that of the ionophores, because they bear a strong hydrophobic structure.

Validation of the potentiometric data was assessed with regard toprecision, accuracy, within-day and between-dayvariability, and recovery (Table 2). These parameters were selected due to the intended analytical application. In general, all sensors displayed similar and good analytical behavior.

In general, an exceptional potential stability was observed for a solid-contact sensor. This may be attributed to the membrane good adhesion, its impossible lamination by water and its high thickness. The membrane is applied over a cavity where graphite occupies only its deep side [9] and the walls are made of Perspex. Since Perspex dissolves with tetrahydrofuran, the liquid membrane solution reacts with the wall, leading to a dry membrane that constitutes a solid block resistant to water lamination. Hydrated layers are formed therefore by water molecules moving through the plasticized membrane only. Still, the water reaches the graphite because it is responsible for establishing the internal potential, along with $\mathrm{O}_{2}[33,34]$. Since the membrane is quite thick (ca. $2 \mathrm{~mm}$ ), it seems that the water gradient remains constant for a long period of time and the film of water reaching the graphite is unable to drift the potential withsignificance.

\subsection{Sensors selectivity}

The selectivity behavior of sensors is defined by the ion exchange constants which depend on the selectivity of complexation as well as on the standard free energies of the respective ions in the aqueous and organic phases [35]. The former requisite suggests the use of ligands that strongly bind the preferred ion and only weakly all the others [35], as the mechanism of selectivity is mainly governed by stereospecific and electrostatic aspects, being the lipophilic environment dictated by the plasticizer. For metalo-

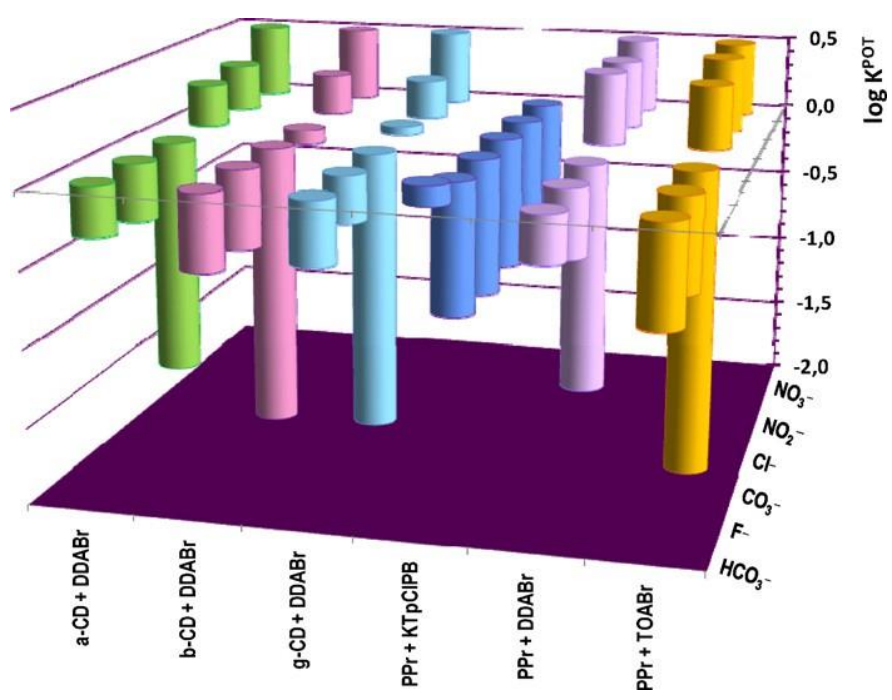

Fig. 5. Potentiometric selectivity coefficients $\left([\mathrm{SDZ}]=1 \times 10^{-3} \mathrm{~mol} \mathrm{~L}^{-1}\right)$.

porphyrins, the kind and oxidation state of the coordinated central are also relevant.

The selectivity of a potentiometric sensor for the main ion (analyte) over other ions present in the solution is usually expressed in terms of the potentiometric selectivity coefficient, $K^{\text {pot }}$ The selectivity coefficients were determined by the separated solutions method [36]. The emf values of SDZ or interfering species solutions were measured separately and the corresponding selectivity coefficients were calculated by using the following equation:

$$
K_{\mathrm{SDZ} Z^{-} \jmath^{-}}^{\mathrm{POT}}=\frac{E_{2}-E_{1}}{S}+\left(1-\frac{-1}{Z}\right) \times \log C_{S D Z}
$$

where $E_{1}$ and $E_{2}$ are the sensor potentials in $1.0 \times 10^{-3} \mathrm{~mol} \mathrm{~L}^{-1}$ solutions of SDZ and interfering ion $J^{Z-}$, respectively, $C_{\mathrm{SDZ}}$ the concentration of SDZ and $S$ the practical slope of the calibration plot calculated in $\mathrm{mV}$ decade ${ }^{-1}$.

The potentiometric selectivity coefficients of the proposed sensor are shown in Fig. 5. Carbonate, chloride, nitrate, nitrite, fluoride and hydrogencarbonate (bicarbonate) were selected as possible interfering species because they are usually present in drinking water, as well as in wastewaters, industrial effluents, soils, etc.

The presence of cationic sites from DDABr or TOABr into the membranelead to the following general relative order of interfering effect: nitrate $>$ nitrite $>$ chloride $>$ fluoride hydrogen hydrogencarbonate $>$ carbonate (Table 3 ). This seems a near-Hofmeister behavior [37]. It is believed that the presence of ionic sites of opposite charge as the analyte ion (as required for neutral carriers), forces uncomplexed ions to be extracted for electroneutrality reasons, which gives a selectivity sequence that reflects the relative lipophilicity of the sample ions and is not influenced by the complexation with the charged ligand [38]. The experimental results also point out that the selectivity behavior did not depend on the ionophore in use, neither $\mathrm{Mn}^{\mathrm{III}} \mathrm{TPPCl}$ nor $a-\mathrm{CD}, 13-\mathrm{CD}$ or 1-CD. The fact of having $a, 13$ or 1-CD provided no significant differences between these with regard to selectivity.

Generally, the ionic sites of the same charge sign as the primary ion improved the selectivity. Membranes having PPHR as ionophore and negatively charged additives displayed a completely different selectivity behavior. All possible interfering compounds showed similar potentiometric selectivity coefficients, lying within $-0.92 \underline{0} .06 \log K^{\mathrm{POT}}$. Hydrogen carbonate was the only exception to this observation. 
Validation data of several SDZ sensors.

\begin{tabular}{|c|c|c|c|c|c|c|}
\hline \multirow[t]{3}{*}{ Validation } & \multicolumn{6}{|l|}{ ISEs } \\
\hline & $\mathrm{Mn}^{\mathrm{III}} \mathrm{TPPCl}$ & $\mathrm{Mn}^{\mathrm{III}} \mathrm{TPPCl}$ & $\mathrm{Mn}^{\mathrm{III}} \mathrm{TPPCl}$ & $a-\mathrm{CD}$ & $13-\mathrm{CD}$ & $1-\mathrm{CD}$ \\
\hline & $\mathrm{TOABr}(\mathbf{3})$ & $\operatorname{DDABr}(\mathbf{6})$ & $\begin{array}{l}\text { KTpClPB } \\
(\mathbf{1 0})\end{array}$ & $\operatorname{DDABr}(\mathbf{1 6})$ & $\operatorname{DDABr}(\mathbf{2 3})$ & $\operatorname{DDABr}(\mathbf{3 0})$ \\
\hline $\mathrm{Cv}_{\mathrm{w}}, \%$ & 1.99 & 4.29 & 2.12 & 5.67 & 2.58 & 1.62 \\
\hline Accuracy, \% & 1.81 & 4.83 & 26.64 & 0.24 & 2.21 & 5.22 \\
\hline Within-day variability, \% & 1.70 & 1.91 & 2.31 & 1.99 & 1.32 & 1.89 \\
\hline Between-day variability, \% & 2.05 & 2.13 & 3.69 & 2.50 & 1.64 & 3.69 \\
\hline Recovery, \% & 99.1 & 97.9 & 98.9 & 104.3 & 101.1 & 98.6 \\
\hline
\end{tabular}

Table 3

Selectivity coefficients for SDZ selective sensors for various interfering ions using separate solution method.

\begin{tabular}{|c|c|c|c|c|c|c|}
\hline \multirow[t]{2}{*}{ ISEs } & \multicolumn{6}{|c|}{$\log K_{\mathrm{SDZ}, J z^{-}}^{\mathrm{POT}}$} \\
\hline & $\mathrm{CO}_{3}{ }^{2-}$ & $\mathrm{Cl}^{-}$ & $\mathrm{F}^{-}$ & $\mathrm{HCO}_{3}{ }^{-}$ & $\mathrm{NO}_{3}^{-}$ & $\mathrm{NO}_{2}{ }^{-}$ \\
\hline $\mathrm{Mn}^{\mathrm{III}} \mathrm{TPPCl}+\mathrm{TOABr}(3)$ & -2.04 & 0.43 & -0.63 & -0.66 & 1.39 & 0.65 \\
\hline $\mathrm{Mn}^{\mathrm{III}} \mathrm{TPPCl}+\mathrm{DDABr}(6)$ & -1.49 & 0.48 & -0.45 & -0.31 & 0.99 & 0.45 \\
\hline $\mathrm{Mn}^{\mathrm{III}} \mathrm{TPPCl}+\mathrm{KTpCIPB}(10)$ & -0.90 & -0.88 & -0.86 & 0.12 & -1.02 & -0.95 \\
\hline$a-\mathrm{CD}+\mathrm{DDABr}(16)$ & -1.56 & 0.28 & -0.37 & -0.32 & 1.37 & 0.31 \\
\hline $13-\mathrm{CD}+\mathrm{DDABr}(23)$ & -1.86 & -0.10 & -0.52 & -0.50 & 1.34 & 0.27 \\
\hline 1-CD + DDABr (30) & -1.84 & 0.06 & -0.30 & -0.42 & 1.48 & 0.26 \\
\hline
\end{tabular}

\subsection{Response mechanism}

For PPHRs, the nature of the ionophore anion interaction mechanism correlates with the charge of the metal ion chelated by the PPHR[39,40]. TrivalentmetalioncomplexeswithPPHRwerefound to serve as either neutral or charged carriers depending on the existence and number of bound axial ligands. In the case of sensors based on neutral carriers, ionic sites with an opposing charge to that of the primary ions are necessary to decrease the membrane resistance, which in turn reduces the co-ion interferences, and achieves a Nernstian response with an acceptable selectivity, and improves the detection limit. In the present study, ion-selective membranes formulated with $\mathrm{Mn}$ (III)PPHR required a cationic additive to enhance the potentiometric response. Thus, these results pointed out that the PPHR ionophore acted as neutral carrier in the membrane.

As expected, CDs also acted as neutral carrier. These neutral anion receptorsincorporatestrong, multiple, hydrogenbond donor groups $(-\mathrm{OH})$ onitssurface. Typically, onceinsidetheCDcavity, the guest molecule makes conformational adjustments to take maximum advantage of the weak van der Waals forces that exist [14].

The effect of plasticizer and additive upon the observed potentiometric response was tested by evaluating two news sensors, carrying plasticized membranes (i) with noionophore and no additive or (ii) with no ionophore and with negatively charged additive. The first sensor was quite unstable and the potential was unable to decrease with increasing SDZ concentrations. Its potential change ranged $\pm 3 \mathrm{mV}$ along each calibration. The second sensor showed sub-Nernstian behavior, with slopes of $25 \mathrm{mV}$ decade $^{-1}$ after a concentration of $1 \mathrm{~A}^{-4} \mathrm{~mol} \mathrm{~L}{ }^{-1} \mathrm{SDZ}$. Especially for CD-based sensors, this indicated that the ionophore played a significant role on the observed response.

\subsection{Complementary sample analysis}

The previous selectivity study is mainly theoretical and suggested high interfering effects from nitrate, nitrite and chloride upon the potentiometric response. Thus, before proceeding with samples analysis, the most contaminated waters samples were analyzed in terms of their main chemical composition. The parameters selected for this purpose were those indicated on the Portuguese law for waters. The average levels found were indicated in Table 4.
The obtained results are always below the legal limits and suggested that the proposed potentiometric method could be applied to the analysis of waters in aquaculture environment.

\subsection{Application}

The determination of SDZ in aquaculture waters was carried out on the previously prepared samples by direct potentiometry. The obtained results are summarized in Table 5. The conventionally shaped sensors selected for this purpose were sensors 3 and 23 (see Table 1); they presented increased sensitivity of response $\left(\mathrm{mV}\right.$ decade $\left.\mathrm{e}^{-1}\right)$, good potential reproducibility and stability.

The samples were spiked by adding small increments of $1.0 \notin 0^{-2} \mathrm{~mol} \mathrm{~L}^{-1}$ standard SDZ solution to $20.0 \mathrm{~mL}$ aliquot samples of various concentrations. The change in potential reading was recorded for each increment and used to calculate the concentration of SDZ sample in the sample solutions using the following equation:

$C_{\mathrm{SDZ}}=\frac{C_{\underline{\mathrm{s}}} \times V_{\mathrm{s}}}{\left(V_{\mathrm{SDZ}}+V_{\mathrm{s}}\right) \times 10^{\frac{l 1 E}{\mathrm{~s}}-V_{\mathrm{SDZ}}}}$

Here $C_{\mathrm{SDZ}}$ is the SDZ concentration of testing sample, $C_{\mathrm{s}}$ is the concentration of the standard, $V_{\mathrm{x}}$ and $V_{\mathrm{s}}$ are the corresponding volumes, $S$ is the slope of the potentiometric response, and $E$ is te change in potential [41].

Table 4

Chemical parameters of the water samples.

\begin{tabular}{lccc} 
& Sample A & Sample B & Sample C \\
\hline Turbidity (UNT) & $<0.2$ & $<0.2$ & 0.7 \\
pH (Sorensen scale) & 7 & 6.9 & 6.7 \\
Conductivity $\left(\mu \mathrm{S} \mathrm{cm}^{-1}\right)$ & 41 & 41 & 135 \\
Nitrate $\left(\mathrm{mg} \mathrm{L}^{-1}\right)$ & 1.7 & 1.3 & 12.1 \\
Nitrite $\left(\mathrm{mg} \mathrm{L}^{-1}\right)$ & $<0.03$ & $<0.03$ & $<0.03$ \\
Ammonium $\left(\mathrm{mg} \mathrm{L}^{-1}\right)$ & $<0.05$ & 0.07 & $<0.05$ \\
TOC $\left(\mathrm{mgL}^{-1}\right)$ & $<1$ & $<1$ & $<1$ \\
$\mathrm{Cu}\left(\mathrm{mg} \mathrm{L}^{-1}\right)$ & $<0.01$ & $<0.01$ & $<0.01$ \\
BOD $\left(\mathrm{mg} \mathrm{L}^{-1}\right)$ & $<3$ & $<3$ & $<3$ \\
$\mathrm{COD}\left(\mathrm{mgL}^{-1}\right)$ & $<30$ & $<30$ & $<30$ \\
\hline
\end{tabular}

TOC: total organic content; BOD: biochemical oxygen demand; COD: chemical oxygen demand. 
Table 5

Determination of SDZ in aquaculture by applying the standard addition method and the corresponding statistical data.

\begin{tabular}{|c|c|c|c|c|}
\hline Sample & Added, $\mathrm{mol} \mathrm{L}^{-1}$ & $\begin{array}{l}\text { Found, } \mathrm{mol} \mathrm{L}^{-1} \\
(n=3)\end{array}$ & $\begin{array}{l}\mathrm{RD}(\%) \\
(n=3)\end{array}$ & $\begin{array}{l}\text { Recovery }(\%) \\
(n=3)\end{array}$ \\
\hline \multirow{3}{*}{1} & $2.55 \times 10^{-4}$ & $2.45 \times 10^{-4} \pm 1.2 \times 10^{-5}$ & 4.0 & 96.0 \\
\hline & $5.39 \times 10^{-4}$ & $5.22 \times 10^{-4} \pm 2.6 \times 10^{-5}$ & 3.0 & 97.0 \\
\hline & $1.06 \times 10^{-3}$ & $1.03 \times 10^{-3} \pm 4.6 \times 10^{-5}$ & 3.0 & 97.0 \\
\hline \multirow{3}{*}{2} & $2.55 \times 10^{-4}$ & $2.62 \times 10^{-4} \pm 3.2 \times 10^{-5}$ & -2.9 & 102.9 \\
\hline & $5.39 \times 10^{-4}$ & $5.51 \times 10^{-4} \pm 5.6 \times 10^{-5}$ & -2.3 & 102.3 \\
\hline & $1.06 \times 10^{-3}$ & $1.01 \times 10^{-3} \pm 7.2 \times 10^{-5}$ & 4.4 & 95.6 \\
\hline \multirow{3}{*}{3} & $2.55 \times 10^{-4}$ & $2.39 \times 10^{-4} \pm 1.1 \times 10^{-5}$ & 6.4 & 93.6 \\
\hline & $5.39 \times 10^{-4}$ & $5.30 \times 10^{-4} \pm 3.0 \times 10^{-5}$ & 1.6 & 98.4 \\
\hline & $1.06 \times 10^{-3}$ & $1.07 \times 10^{-3} \pm 2.1 \times 10^{-5}$ & -1.1 & 101.1 \\
\hline \multirow{3}{*}{4} & $2.55 \times 10^{-4}$ & $2.54 \times 10^{-4} \pm 2.2 \times 10^{-5}$ & 0.5 & 99.5 \\
\hline & $5.39 \times 10^{-4}$ & $5.54 \times 10^{-4} \pm 5.0 \times 10^{-5}$ & -2.9 & 102.9 \\
\hline & $1.06 \times 10^{-3}$ & $1.03 \times 10^{-4} \pm 6.9 \times 10^{-5}$ & 3.0 & 97.0 \\
\hline \multirow{3}{*}{5} & $2.55 \times 10^{-4}$ & $2.49 \times 10^{-4} \pm 1.1 \times 10^{-5}$ & 2.2 & 97.8 \\
\hline & $5.39 \times 10^{-4}$ & $5.07 \times 10^{-4} \pm 1.5 \times 10^{-5}$ & 5.8 & 94.2 \\
\hline & $1.06 \times 10^{-3}$ & $1.05 \times 10^{-3} \pm 1.7 \times 10^{-5}$ & 1.2 & 98.8 \\
\hline \multirow{3}{*}{6} & $1.07 \times 10^{-4}$ & $1.01 \times 10^{-4} \pm 1.7 \times 10^{-5}$ & 5.5 & 94.5 \\
\hline & $5.39 \times 10^{-4}$ & $5.19 \times 10^{-4} \pm 2.4 \times 10^{-5}$ & 3.6 & 96.4 \\
\hline & $1.06 \times 10^{-3}$ & $1.00 \times 10^{-3} \pm 3.7 \times 10^{-5}$ & 5.4 & 94.6 \\
\hline
\end{tabular}

Found: mean \pm standard error; RD: relative deviation.

The values reported in Table 5 were calculated from three determinations in aquaculture water samples collected from different farming places. The obtained results confirmed the accuracy and precision of the present work. Recoveries ranged 93.6 and
$102.9 \%$, thus confirming the accuracy of the analytical results. Relative standard deviations were also low, and confirmed the precision of the proposed method. Student $t$ test (at 95\% confidence level) confirmed the accuracy of the analytical data because

Table 6

The main features of the proposed method and previously reported sensors for SDZ determination.

\begin{tabular}{|c|c|c|c|c|c|}
\hline Method & Small description & Samples & Detection limit & Response time & Reference \\
\hline Fluorimetry & $\begin{array}{l}\text { Competitive immunocomplex capture format } \\
\text { making use of an immobilized protein } \mathrm{A} / \mathrm{G} \\
\text { sorbent or a restricted access support in a } \\
\text { novel homogeneous-heterogeneous }(\mathrm{HH}) \\
\text { assay mode. }\end{array}$ & $\begin{array}{l}\text { Water } \\
\text { Honey }\end{array}$ & $0.11 \mu \mathrm{g} \mathrm{L}^{-1} 0.85 \mu \mathrm{gL}^{-1}$ & $18 \min 2 \mathrm{~min}$ & [42] \\
\hline SPR & $\begin{array}{l}\text { Immunoassays based on the plasmon of gold } \\
\text { diffraction grating surface for simultaneous } \\
\text { detection of antibiotics from different groups, } \\
\text { including sulfapyridine as a sulphonamide } \\
\text { compound. }\end{array}$ & Milk & $0.29 \mu \mathrm{g} \mathrm{L}^{-1}$ & $\approx 30 \mathrm{~min}$ & [43] \\
\hline SPR & $\begin{array}{l}\text { Inhibition assay format in an optical biosensor } \\
\text { chip. }\end{array}$ & Chicken serum & $7-1000 \mu \mathrm{g} \mathrm{L}^{-1}$ & $\approx 10 \mathrm{~min}$ & [47] \\
\hline WIOS & $\begin{array}{l}\text { Lab-on-a-chip for multi-antibiotic competitive } \\
\text { immunoassay based on competitive } \\
\text { immunoassay based on wavelength } \\
\text { interrogated optical sensor technology and a } \\
\text { polymer-based self-contained microfluidic } \\
\text { cartridge. }\end{array}$ & Milk & $100 \mu \mathrm{g} \mathrm{L}^{-1}$ & $10 \mathrm{~min}$ & {$[44]$} \\
\hline WIOS & $\begin{array}{l}\text { Competitive immunoassay format using } \\
\text { immunoreagents previously developed for the } \\
\text { generic detection of sulfapyridine and } \\
\text { evaluated by enzyme-linked immunosorbent } \\
\text { assay. The immunoreagents were immobilized } \\
\text { onto the surface of the waveguide chip, and a } \\
\text { fluidic cell allowed flowing analyte and } \\
\text { detection solutions above the surface. }\end{array}$ & Milk & $0.5 \mu \mathrm{gL}^{-1}$ & $\approx 30 \mathrm{~min}$ & {$[45]$} \\
\hline Electrochemistry & $\begin{array}{l}\text { The immunological reaction for the detection } \\
\text { of sulfonamide antibiotics performed on the } \\
\text { magnetic bead is based on a direct Competitive } \\
\text { assay using a tracer with horserodish } \\
\text { peroxidase for the enzymatic labeling and } \\
\text { modified magnetic beads captured by a } \\
\text { magneto sensor made of graphite-epoxy } \\
\text { composite acting as the transducer. }\end{array}$ & Cream milk & $1.44 \mu \mathrm{g} \mathrm{L}^{-1}$ & - & [46] \\
\hline Potentiometry & $\begin{array}{l}\text { PVC membrane selective electrodes for SDZ for } \\
\text { flow and batch measurements with iron } \\
\text { phthalocyanine as ionophores }\end{array}$ & $\begin{array}{l}\text { Drugs Biol. } \\
\text { fluids }\end{array}$ & $0.87-7.0 \mathrm{mg} \mathrm{L}^{-1}$ & $<30 s$ & [9] \\
\hline Potentiometry & $\begin{array}{l}\text { PVC membranes with } \mathrm{Mn}^{\mathrm{III}} \mathrm{TPPCl}, a-\mathrm{CD}, 13-\mathrm{CD} \text {, } \\
\text { 1-CD molecules as ionophores. }\end{array}$ & $\begin{array}{l}\text { Aquaculture } \\
\text { Water }\end{array}$ & $3 \mathrm{mgL}^{-1}$ & $<30 s$ & This work \\
\hline
\end{tabular}

UV/Vis: Ultraviolet Visible; SPR: Surface Plasmon Resonance; WIOS: sensitive wavelength interrogated optical sensor. 
the calculated $t(0.28)$ did not exceed the theoretical value (2.07).

In order to know if the proposed method exhibited any fixed or proportional bias, a simple linear regression of the taken amounts against found was calculated. A small displacement of the zero origin (equal to $1 \times 10^{-5}$ ) and of the unit slope (0.9736) was found, confirming the absence of the above bias.

\subsection{Comparison to previous sensors}

The proposed work is compared in terms of analytical figures of merit with other sensors previously reported in the literature for the determination of different sulphonamides (Table 6). In general terms, it is possible to conclude that the main advantage of the presented work is the low response time and the low cost the proposed sensors. They display very quick responses and are inexpensive in terms of regular laboratory materials. Their main disadvantage compared to others is the high limit of detection. This last feature is mostly correlated to the use of conventional materials instead of nanostructured ones, which are not included in elegant platforms. Thus, further work is conducted to incorporate the membranes upon microfluific devices. Of course, this will turn out more expensive, but much cheaper than all other reported methods. These rely only on immunoassays and therefore require highly expensiveconsumablereagents. Furthermore, someof these use very expensive transducers that are quite far from the regular potentiometer in everyday laboratory.

The proposed sensors offer similar analytical features to those in [9]. The here presented sensor offers however higher stability in terms of analytical signal. The use of regular CD compounds as sensors is also an advantage in terms of routine laboratory.

\section{Conclusions}

Mn(III) PPHR and CD were suitable ionophores for the preparation of SDZ sensors. They acted both as neutral carriers. The presence of positively charged additives in the selective membrane enhanced the potentiometric performance. Selectivity profiles followed a near-Hofmeister pattern with theexception of PPHR-based sensors with negatively charged additives. Despite their good selectivity behavior, they suffered from a great $\mathrm{pH}$ interference effect.

The proposed sensors were found useful for the control of SDZ in waters from aquaculture origin. The corresponding detectors were constructed in a simple and inexpensive way. The overall procedure was considered precise, accurate, and inexpensive regarding reagent consumption and equipment involved. Considering its routine application, the main advantages arise from the composition and quantity of emitted effluents, with small concern in terms of environmental issues. The proposed method also enabled high sampling frequencies with low operator intervention, meaning that it was suitable for the routine procedures carried out in analytical laboratories; it is particularly suitable for screening assays.

\section{Acknowledgements}

The authors acknowledge the financial support from FCT, Fundação para a Ciência e Tecnologia, by means of project PTDC/AGR-AAM/68359/2006. One of us (Almeida SAA) is grateful to FCT for the PhD grant (SFRH/BD/42509/2007).

\section{References}

[1] S.A.E. Kools, J.F. Moltmann, T. Knacker, Regul. Toxicol. Pharmacol. 50 (2008) $59-65$.

[2] H.C.Wegener, F.M. Aarestrup,P.Gerner-Smidt, F. Bager, Acta Vet.Scand.Suppl. 92 (1999) 51-57.

[3] I. Braschi, S. Blasioli, L. Gigli, C.E. Gessa, A. Alberti, A. Martucci, J. Hazard. Mater. 178 (2010) 218-225.

[4] E. Zuccato, S. Castiglioni, R. Bagnati, M. Melis, R. Fanelli, J. Hazard. Mater. 179 (2010) 1042-1048.

[5] Z. Zhang, V.V. Cosofret, Select Elect. Rev. 12 (1990) 35-135.

[6] V.V. Cosofret, R.P. Buck, Pharmaceutical Applications of Membrane Sensors, CRC Press, Boca Raton, FL, 1992, p. 448.

[7] A.R. Fakhari, M. Alagheman, M. Shamsipur, Anal. Lett. 34 (2001) 1097-1106.

[8] V.V. Cosofret, R.P. Buck, Crit. Rev. Anal. Chem. 24 (1993) 1-58.

[9] A.H. Kamel, F.T.C. Moreira, S.A.A. Almeida, M.G.F. Sales, Anal. Sci. 25 (2009) 365-371.

[10] S. Amemiya, Potentiometric ion-selective electrodes, in: C.G. Zoski (Ed.), Handbook of Electrochemistry, Elsevier, 2007 (Chapter 7).

[11] M.R. Ganjali, P. Norouzi, M. Rezapour, Encyclopedia of Sensors, Potentiometric Ion Sensors, American Scientific Publishers, Los Angeles, vol. 8, 2006, 197-288.

[12] M.R. Ganjali, P. Norouzi, M. Rezapour, F. Faridbod, M.R. Pourjavid, Sensors 6 (2006) 1018-1086.

[13] J.W. Steed, D.R. Turner, K.J. Wallace, Core Concepts in Supramolecular Chemistry and Nanochemistry, University of Southern Mississippi, John Wiley \& Sons, USA, England, 2007.

[14] E.M.M. Del Valle, Proc. Biochem. 39 (2004) 1033-1046.

[15] M. Biesaga, K. Pyrzynska, M. Trojanowicz, Talanta 51 (2000) 209-224.

[16] E.D. Steinle, U. Schaller, M.E. Meyerhoff, Anal. Sci. 17 (1998) 79-84.

[17] J. Yoon, J.H. Shin, I.R. Paeng, H. Nam, G.S. Cha, K.J. Paeng, Anal. Chim. Acta 367 (1998) 175-181.

[18] M.M.G. Antonisse, B.H.M. Smellink-Rubel, J.F.J. Engbersen, D.N. Reinhoudt, J. Chem. Soc., Perkin Trans. 2 (1998) 773-778.

[19] Z. Deyl, I. Miksik, A. Eckhardt, V. Kasicka, V. Král, Curr. Anal. Chem. 1 (2005) 103-119.

[20] Y.A. Zolotov, Macrocyclic Compounds in Analytical Chemistry, John Wiley and Sons Ltd, New York, 1997, p. 448.

[21] R.P. Buck, V.V. Cosofret, Pure Appl. Chem. 65 (1993) 1849-1858.

[22] E.M.G. Santos, A.N. Araújo, C.M.C.M. Couto, M.C.B.S.M. Montenegro, J. Pharm Biomed. Anal. 42 (2006) 535-542.

[23] E. Bakker, P. Buhlmann, E. Pretsch, Chem. Rev. 97 (1997) 3083-3132.

[24] Y. Qin, E. Bakker, Anal. Chem. 76 (2004) 4379-4386.

[25] I. Beletskaya, V.S. Tyurin, A. Yu, A. Tsivadze, R. Guilard, C.Stern, Chem. Rev.109 (2009) 1659-1713.

[26] W. Zhang, E. Rozniecka, E. Malinowska, P. Parzuchowski, M.E. Meyerhoff, Anal Chem. 74 (2002) 4548-4557.

[27] T. Akimoto, Yakugaku Zasshi 125 (2005) 971-980.

[28] G. Huschek, D. Hollmann, N. Kurowski, M. Kaupenjohann, H. Vereecken, Chemosphere 72 (2008) 1448-1454.

[29] E. Bakker, E. Pretsch, Trends Anal. Chem. 21 (2001) 11-19.

[30] M. Telting-Diaz, E. Bakker, Anal. Chem. 73 (2001) 5582-5589.

[31] D. Ammann, W.E. Morf, P. Anker, P.C. Meier, E. Pretsch, W. Simon, Ion-Sel. Electrode Rev. 5 (1983) 3-92.

[32] P.M. Gehring, W.E. Morf, M. Welti, E. Pretsch, W. Simon, Helv. Chim. Acta 73 (1990) 203-212.

[33] A. Hulanicki, E.M Trojanowicz, Anal. Chim. Acta 87 (1976) 411-417.

[34] G. Herdecke, J. Kropf, G. Stork, J.G. Schindler, Z. Fresenius, Anal. Chem. 303 (1980) 364-370.

[35] E. Bakker, E. Pretsch, Angew. Chem. Int. Ed. 46 (2007) 5660-5668.

[36] Y. Umezawa, K. Umezawa, H. Sato, Pure Appl. Chem. 67 (1995) 507-518.

[37] E. Malinowska, E. Niedziółka, M.E. Meyerhoff, Anal. Chim. Acta 432 (2001) $67-78$.

[38] M.M.G. Antonisse, D.N. Reinhoudt, Electroanalysis 11 (1999) 1035-1048.

[39] H. Jafar, M.K. Amini, H. Motaghi, S. Tangestaninejad, M. Moghadam, Sens. Actuat. B 87 (2002) 448-456.

[40] E. Bakker, E. Malinowska, R.D. Schiller, M.E. Meyerhoff, Talanta 41 (1994) 881-890.

[41] R.P. Buck, E. Lindner, Pure Appl. Chem. 66 (1994) 2527-2536.

[42] D. Jorneta, M.A. González-Martíneza, R. Puchades, A. Maquieira, Talanta 81 (2010) 1585-1592.

[43] F.Fernández,K.Hegnerová,M.Piliarik,F.Sanchez-Baeza,J.Homola,M.P.Marco, Biosens. Bioelectron. 26 (2010) 1231-1238.

[44] G. Suárez, Y.H. Jin, J. Auerswald, S. Berchtold, H.F. Knapp, J.M. Diserens, Y. Leterrier, E.M. Jan-Anders, G. Voirin, Lab Chip 9 (2009) 1625-1630.

[45] J. Adrian, S. Pasche, J.M. Diserens, F. Sánchez-Baeza, H. Gao, M.P. Marco, G. Voirin, Biosens. Bioelectron. 24 (2009) 3340-3346.

[46] E. Zacco, J. Adrian, R. Galve, M.P. Marco, S. Alegret, M.I. Pividori, Biosens. Bioelectron. 22 (2007) 2184-2191.

[47] M. Bienenmann-Ploum, T. Korpimaki, W. Haasnoot, F. Kohen, Anal. Chim. Acta 529 (2005) 115-122. 